\title{
Planejamento Estratégico de uma Universidade Federal na Amazônia: Aplicação da Análise Fatorial
}

\author{
Strategic Planning of a Federal University in the Amazon: Application of Factor \\ Analysis
}

\author{
Antônio Cordeiro Santana ${ }^{1}$ \\ Ádamo Lima de Santana ${ }^{2}$ \\ Ádina Lima de Santana ${ }^{3}$ \\ Nilson Luiz Costa 4 \\ Ana Karlla Magalhães Nogueira ${ }^{5}$
}

Resumo: O objetivo do trabalho foi aplicar a análise fatorial como instrumento metodológico no planejamento estratégico institucional para dar maior consistência e rigor científico ao processo de identificação dos pontos fortes, pontos fracos, oportunidades e ameaças, utilizados na construção de cenários futuros para o desenvolvimento sustentável de uma Universidade Rural da Amazônia. Os resultados gerados permitiram configurar os ambientes interno e externo da instituição e a elaboração de cenários futuros. Concluiu-se que análise fatorial pode ser um poderoso instrumento a ser utilizado na identificação dos elementos necessários à elaboração dos objetivos, metas e estratégias do planejamento estratégico institucional.

Palavras-chave: Gestão estratégica, análise multivariada, competitividade institucional

Abstract: Applied factor analysis as a methodological tool in institutional strategic planning to give greater consistency and scientific rigor in identifying the strengths, weaknesses, opportunities and threats used in the construction of future scenarios for the sustainable development of a Rural University Amazon. The results allowed to configure the internal and external environments of the institution and the development of future scenarios. It was concluded that the factor analysis can be a powerful tool to be used in identifying the information needed to produce the goals, objectives and strategies of institutional strategic planning.

Key words: Strategic management, multivariate analysis, institutional competitiveness.

JEL: C38

\section{INTRODUÇÃO}

A Universidade Federal Rural da Amazônia (UFRA) está construindo sua plataforma de Universidade Multicampi, tendo como missão contribuir para o desenvolvimento sustentável da Amazônia, a partir da formação de profissionais qualificados e competitivos para atuar nos diversos e complexos sistemas produtivos, socioeconômicos, ambientais e culturais, a produção de conhecimentos científicos, tecnológicos e de inovação e oferecendo serviços

\footnotetext{
1 Agrônomo. Doutor em Economia Aplicada pela UFV. Professor da Universidade Federal Rural da Amazônia (UFRA) e do Núcleo de Altos Estudos Amazônicos (NAEA) da Universidade Federal do Pará (UFPA0029.

2 Bacharel em Ciências da Comunicação. Doutor em Engenharia Elétrica pela UFPA. Professor da Universidade Federal do Pará

${ }^{3}$ Engenheira de Alimentos. Doutoranda em Engenharia de Alimentos pela UNICAMP.

4 Economista. Doutor em Ciências Agrárias pela UFRA. Professor da Universidade Federal de Santa Maria (UFSM).

${ }^{5}$ Agrônoma. Doutoranda em Desenvolvimento Socioambiental pelo NAEA/UFPA. Professora da Universidade Rural da Amazônia
} 
de extensão, com vistas a melhorar a qualidade de vida das pessoas. Essa trajetória é complexa e para conduzi-la de forma sustentável, necessita-se criar estratégias competitivas para orientar os planos, os projetos e as ações de curto, médio e longo prazos, tendo como foco melhorar continuamente a qualidade do que faz e marcar posição de referência como instituição de ensino superior da Amazônia e do Brasil.

Para isso, a elaboração do Planejamento Estratégico Institucional da UFRA 2014-2024 (PLAIN) foi utilizada como o instrumento de base para nivelar o conhecimento da comunidade interna sobre as forças que influenciam os ambientes internos e externos da instituição a partir de visões interdisciplinares dos grupos de interesse e de profissionais com amplo conhecimento sobre a complexidade econômica, social, cultural e ambiental da Amazônia. Essas visões foram socializadas por meio de ciclos de palestras e os resultados utilizados na elaboração dos questionários que foram aplicados aos grupos de interesse com vistas a ampliar o conhecimento sobre os pontos fortes, pontos fracos, oportunidades e ameaças ao desempenho da UFRA.

Com efeito, as informações geradas a partir dos questionários foram utilizadas para dar consistência ao diagnóstico da realidade vivenciada atualmente pela instituição e contribuir para a construção das estratégias para viabilizar a trajetória multicampi de desenvolvimento da UFRA, as quais foram obtidas dos seguintes grupos de interesse: alunos, professores, egressos e empregadores. As informação dos técnicos foram aproveitadas de estudos internos sobre mapeamento de competências.

Trata-se de um estudo exploratório sobre a arena competitiva em que a UFRA atua concorrendo com outras instituições de ensino superior públicas e privadas no espaço de domínio da indústria da educação (PORTER, 1999; SANTANA et al., 2002). No âmbito dessa concepção de desenvolvimento institucional multicampi, o cenário de crescimento com exigência de sustentabilidade a partir da implantação de grandes projetos de biodiesel, energia, infraestrutura portuária, extração mineral, concessão florestal, plantio de florestas e de grãos exige conhecimento e informação sobre a realidade, eficiência, eficácia e qualidade na formulação e condução das estratégias e sobre o envolvimento da comunidade acadêmica em parceria com a sociedade organizada e as minorias sociais ainda excluídas das políticas públicas.

A forma de abordagem do estudo é qualitativa com tratamento quantitativo das informações de campo. A partir dos resultados gerados sobre as questões-chave que configuram os pontos fortes e os pontos fracos do ambiente interno e as forças macroanalíticas que definem as oportunidades e ameaças do ambiente externo, formatam-se as contribuições emanadas dos grupos de interesse para apoiar a UFRA na construção e consolidação de sua estrutura multicampi. Os cenários macroanalíticos são construídos com o apoio dos resultados produzidos pela análise fatorial exploratória na construção de objetivos, metas e as estratégias de ação.

Por fim, os resultados deste estudo constituiu a fase intermediária do PLAIN (SANTANA, 2014), que fornece o conhecimento técnico-científico captado dos grupos de interesse sobre os fatores que influenciam os ambientes interno e externo da UFRA e prepara os planos de ações a serem implantados. 
O objetivo do estudo foi avaliar, com base na percepção dos grupos de interesse (alunos, professores, egressos e empregadores), as forças que caracterizam os ambientes interno e externo de atuação da UFRA, com vistas a apoiar a elaboração de mapa estratégico com os cenários, objetivos e metas do PLAIN.

\section{FUNDAMENTAÇÃO TEÓRICO-METODOLÓGICA}

O universo da pesquisa contemplou os cinco campi e cursos da UFRA, a partir da percepção dos grupos de interesse internos e externos.

O estudo trata apenas a metodologia adotada para apoiar a aplicação da matriz fofa redimensionada com vistas a definir com maior rigor os pontos fortes, os pontos fracos, as oportunidades e as ameaças, além de orientar a elaboração dos objetivos, metas e estratégias para a implantação e acompanhamento do PLAIN.

O universo da pesquisa foi constituído pelos egressos (estudantes formados na UFRA entre 2002, quando foi transformada em Universidade, e 2013), pelos alunos matriculados nos cursos da UFRA, professores que ingressaram na UFRA até 2013, empresas e instituições públicas, privadas e do terceiro setor que contratam profissionais, firmam parcerias e/ou demandam serviços da UFRA.

Para as populações de alunos, professores e egressos, adotou-se 0 critério estatístico para a representatividade da amostra e, para os empregadores, os atores foram selecionados de acordo com a conveniência, considerando fatores como a representatividade no estado, região e país em termos da demanda de profissionais, desenvolvimento de atividades correlatas, possibilidade de estabelecer parcerias e da disposição em preencher 0 questionário. Assim, utilizou-se amostra probabilística para alunos, professores e egressos, assumindo nível de significância de 95\% e um erro amostral de $5 \%$. Adotou-se a proporção de $50 \%$ por se tratar de pesquisa de opinião, em função das respostas dicotómicas e com grau de qualificação na escala Likert, cuja incerteza na resposta induz ao pesquisador ser um pouco mais conservador (SANTANA et al., 2002). No caso específico dos empregadores, a amostra representa as matrizes das instituições e não a totalidade das unidades instaladas na região.

Elaborou-se um questionário específico para cada categoria de entrevistados, que fez o preenchimento com ou sem a presença de um pesquisador encarregado da sua distribuição e recolhimento. Muitos foram encaminhados por e-mail e outros preenchidos diretamente com acesso a um link da plataforma google. Todas as perguntas foram qualitativas e fechadas para facilitar o processamento e elaboradas de tal forma a atenuar a incorporação de interesses específicos nas respostas dadas pelos sujeitos entrevistados em cada grupo de interesse. Para as questões que exigiam qualificação da resposta na escala Likert uma chamada explicativa foi adicionada ao questionário. Todas as questões foram codificadas com um número para representar o conteúdo ou atributo da resposta dada. 
As questões-chave relacionadas aos pontos fortes e pontos fracos que definem o ambiente interno de atuação da UFRA e as questões-chave relativas às oportunidades e ameaças que configuram o ambiente externo da arena competitiva da UFRA foram elaboradas com o apoio das contribuições apresentadas nas palestras realizadas no Ciclo de Oficinas para 0 Planejamento Estratégico da UFRA (Ciclopi).

Sendo assim, após a eliminação de questionários com erro de preenchimento (muitas questões em branco, respostas incompletas sobre algumas questões-chave), a amostra, para o ano de 2013, contemplou 591 alunos (dos campi de Belém, Capanema, Capitão Poço e Parauapebas) de um universo estimado entre 4.000 e 5.000 matriculados, 113 professores (dos campi de Belém, Capanema, Capitão Poço, Paragominas, Parauapebas e Tomé-Açu) de um universo de 259, 156 egressos de diversas instituições públicas, privadas, terceiro setor, pós-graduação, autônomos e desempregados de um universo estimado de 4.500 profissionais e 15 instituições empregadoras de um universo desconhecido. $O$ método probabilístico adotado na determinação do tamanho da amostra dos alunos, professores e egressos encontra-se descrito em Santana (2014a) e Santana et al. (2014).

Uma subamostra com os dados dos professores e egressos, contemplando variáveis comuns, foi extraída da população para a aplicação da análise fatorial. A justificativa técnica para a composição da amostra com esses dois grupos de interesse foi tomada por não haver diferença estatística na média das percepções quanto ao elenco de variáveis incluídas na amostra. Os dados foram processados nos softwares SPSS18 e Stata12, em função da necessidade de aplicação de testes de singularidade das matrizes e testes para verificar a adequação da amostra aos métodos estatísticos. $\mathrm{Na}$ apresentação final dos resultados utilizou-se a planilha Excel para a construção de tabelas e gráficos.

\subsection{Modelo de Análise Fatorial}

A Análise Fatorial Exploratória (AFE) foi utilizada para identificar e caracterizar fatores latentes ou constructos subjacentes à análise de dados multivariados, que fundamentam as relações das variáveis observadas. A AFE pode ser vista como uma ferramenta que permite resumir as informações do fenômeno estudado em um número de fatores substancialmente menor do que o número de variáveis total e sem a perda significativa de informação.

Assim, o propósito da AFE, conforme Johnson e Wichern (2007) e Santana et al. (2014), é descrever, quando for possível, as relações de covariância entre um grande número de variáveis em termos de poucas dimensões subjacentes, embora não observáveis, denominadas de fatores. Portanto, assume-se que um grupo entre todas as variáveis apresentam alta correlação entre si, mas apresentam baixas correlações com as variáveis de outros grupos. Concebe-se, portanto, que esse grupo de variáveis define um único fator ou dimensão latente, que representa as altas correlações observadas entre elas. Portanto, o modelo AFE pode ser utilizado para a 
formulação dos cenários possíveis a partir das variáveis que definem e influenciam os ambientes interno e externo da UFRA, de forma que os fatores latentes estimados contribuem para definir as ações estratégicas para alcançar os resultados vislumbrados em cada cenário.

$\mathrm{Na}$ especificação formal do modelo de AFE, assume-se que cada variável observada é uma combinação linear dos fatores latentes extraídos, tal que cada variável aleatória $i \in\{1, \ldots, N\}$ pertence a uma população homogênea com média $\mu \mathrm{i}$.

$$
y_{i}-\mu_{i}=\psi_{y} f_{i}+e_{i}
$$

Em que $\psi_{y}$ é a matriz de pesos fatoriais $(p \times 1)$, $f_{i}$ é o vetor de fatores latentes $(p \times q)$ e $e_{i}$ é $o$ vetor de erros aleatórios $(p \times 1)$. Assume-se a independência entre $f_{i}$ e $e_{i}$, com $V\left(f_{i}\right)=\Sigma_{f}$ e $V\left(e_{i}\right)=\Sigma_{e}$ dando origem a matriz de covariância de $y_{i}$, dada por $V\left(y_{i}\right)=\psi \psi_{y} \Sigma_{f} \psi^{\prime} y+\Sigma_{e}$ (SANTANA, 2005; SANTANA; SANTANA, 2014). O primeiro termo do lado direito representa a parcela da covariância atribuída aos fatores comuns e o segundo termo a covariância atribuída ao erro. Assim, a comunalidade, ou parcela da variância comum presente na variável é dada pelos elementos da diagonal principal de $\psi_{y} \Sigma_{f} \psi^{\prime} y$, enquanto que a variância específica do erro é dada pelos elementos da diagonal principal de $\Sigma_{e}$.

Os erros são não correlacionados aos fatores latentes, ou seja, $\operatorname{Cov}\left(e_{i} f_{i}^{\prime}\right)$ $=\mathrm{E}\left(e_{i} f_{i}^{\prime}\right)=0$, de modo que as inter-relações entre as $p$ variáveis são totalmente explicadas pelos $q$ fatores latentes. Este resultado significa que os vetores $e_{i} \mathrm{e}$ $f_{i}$ representam duas fontes de variação distintas e, portanto, sem qualquer relacionamento entre elas. Assim, com $\Sigma_{f}=I_{q}$, o modelo reduz-se a $V\left(y_{i}\right)=\psi y$ $\psi^{\prime} y+\Sigma_{e}$. O método tradicional utilizado na estimação dos parâmetros é o de mínimos quadrados ordinários (SANTANA, 2003), que minimiza a soma de quadrados da diferença entre os elementos da população e da matriz de covariância da amostra.

A adequação da amostra ao método de AFE foi feita pelos testes de Bartlett, que seque uma distribuição qui-quadrado, e de Kaiser-Meyer-Oklin (KMO). Estes testes são procedimentos estatísticos que permitem aferir a qualidade das correlações entre as variáveis de forma a seguir com a AFE (SANTANA, 2005; 2008). Aplicou-se também, em todos os modelos, o método da rotação ortogonal varimax porque atinge um padrão teoricamente mais significativo e mais simples de interpretar os fatores.

Neste estudo, o número de fatores extraídos necessários para descrever os dados foi determinado pelo método de Kaiser, que recomenda a escolha daqueles cuja variância explicada é superior a 1. Além disso, o número de fatores extraídos deve explicar pelo menos $60 \%$ da variância total dos dados (HAIR et al., 2005). As variáveis a serem incluídas no modelo fatorial deve apresentar uma comunalidade superior a 0,50 , ou seja, que pelo menos $50 \%$ de sua variância seja explicada pelos fatores comuns extraídos.

Por fim, a identificação das variáveis que estão associadas a cada fator foi realizada com base na magnitude e significância das cargas fatoriais, que 
representa a correlação entre cada variável e o fator. Assim, uma dada variável pertence ao fator cuja carga fatorial for mais alta.

\section{RESULTADOS E DISCUSSÕES}

Para uma visão integrada e sucinta dos resultados, tomou-se um conjunto formado por 11 questões-chave relativas aos pontos fortes e pontos fracos e outro conjunto com nove questões-chave referentes às oportunidades e ameaças, que são comuns aos questionários aplicados aos professores e aos egressos. A justificativa foi realizar uma análise integrada com visualização comparativa entre as percepções de quem olha de dentro e no ângulo de quem observa de fora as questões do desenvolvimento da UFRA no horizonte de 12 anos.

\subsection{Ambiente Interno: Pontos Fortes e Pontos Fracos}

Assumindo que a percepção da maioria valida o atributo identificado como ponto forte ou ponto fraco, os professores identificaram oito pontos fortes e três pontos fracos. Os egressos, por sua vez, identificaram quatro pontos fortes coincidentes e sete pontos fracos, sendo três coincidentes (Figura 1).

A correlação entre os pontos fortes percebidos pelos professores e pelos egressos foi de 0,903, significativa a $1 \%$, o que indica elevado grau de associação entre as percepções.

Os pontos fortes coincidentes foram: expansão multicampi da UFRA, atuação administrativa das coordenadorias de curso, compromisso da UFRA com o desenvolvimento sustentável e criação de cursos novos além das Ciências Agrárias. Esses pontos fortes identificados, embora com características relativamente mais contundentes de comportamento inercial, permitem acreditar que a UFRA tem condições de avançar em busca de cumprir sua missão de contribuir com o desenvolvimento sustentável. Para tanto é importante criar uma estratégia de desenvolvimento articulando a criação dos campi e cursos com coordenadores empenhados e com foco no desenvolvimento sustentável.

Nos pontos fracos, as coincidências ocorreram com a estratégia de comunicação e marketing, a política de interação da UFRA com o egresso e a interação da UFRA com produtores, empresas e comunidades. Estes pontos, tanto na percepção dos professores como dos egressos, demonstra que a UFRA vive em seu casulo e não explora adequadamente suas forças e nem as compartilha com a sociedade, fato que torna a instituição engessada e com pouco potencial para alavancar os pontos fortes e superar as fraquezas. 
Figura 1. Visão do ambiente interno dos pontos fortes e pontos fracos da UFRA de acordo com a percepção dos professores e dos egressos, Pará, 2014.

\begin{tabular}{|c|c|c|c|c|c|}
\hline $\begin{array}{l}\text { 9.11 Política de relacionamento da } \\
\text { UFRA com os egressos }\end{array}$ & $26,5 \%$ & $73,5 \%$ & $25,6 \%$ & $74,4 \%$ & \multirow{11}{*}{$\begin{array}{l}\text { Visãoln. Pforte } \\
\text { VisãoIn. Pfraco } \\
\text { Visão Ex. Pforte } \\
\text { VisãoEx. Pfraco }\end{array}$} \\
\hline $\begin{array}{l}9.10 \text { Interação da UFRA com } \\
\text { produtores, empresas e comunidades }\end{array}$ & $37,2 \%$ & $62,8 \%$ & $26,9 \%$ & $73,1 \%$ & \\
\hline $\begin{array}{l}9.9 \text { Estratégia de comunicação e } \\
\text { marketing institucional da UFRA }\end{array}$ & $21,2 \%$ & $78,8 \%$ & $5,8 \%$ & $4,2 \%$ & \\
\hline $\begin{array}{l}\text { 9.8 Currículos atualizados e planos de } \\
\text { ensino adequados }\end{array}$ & $61,1 \%$ & $38,9 \%$ & 6 41,0\% & $59,6 \%$ & \\
\hline $\begin{array}{l}\text { 9.7 Atuação transparente da gestão } \\
\text { superior da UFRA }\end{array}$ & $54,0 \%$ & $46,0 \%$ & $23,7 \%$ & $76,3 \%$ & \\
\hline $\begin{array}{l}\text { 9.6 Atuação administrativa das } \\
\text { coordenadorias de curso }\end{array}$ & $69,9 \%$ & $30,1 \%$ & $58,3 \%$ & $41,7 \%$ & \\
\hline $\begin{array}{c}\text { 9.5 Atuação administrativa das pro- } \\
\text { reitorias da UFRA }\end{array}$ & $71,1 \%$ & $28,9 \%$ & $\% \quad 48,7 \%$ & $51,9 \%$ & \\
\hline 9.4 Expansão multicampi da UFRA & 86,7 & 13,3 & $3 \% 69,2 \%$ & $31,4 \%$ & \\
\hline $\begin{array}{l}\text { 9.3 Criação de cursos além das Ciências } \\
\text { Agrárias } \\
9.2 \text { Formacão do profissional de }\end{array}$ & $68,1 \%$ & $31,9 \%$ & $\% \quad 53,2 \%$ & $46,8 \%$ & \\
\hline $\begin{array}{l}9.2 \text { Formação do profissional de } \\
\text { graduação adequado ao mercado }\end{array}$ & $65,5 \%$ & $34,5 \%$ & $6 \quad 44,2 \%$ & $55,8 \%$ & \\
\hline \multirow[t]{2}{*}{$\begin{array}{l}\text { 9.1 Compromisso da UFRA com o } \\
\text { desenvimento Sustentável }\end{array}$} & $59,3 \%$ & $40,7 \%$ & $57,1 \%$ & $42,9 \%$ & \\
\hline & 50, & $0,0 \%$ &, $0 \%$ & & $\% \quad 250,0 \%$ \\
\hline
\end{tabular}

Fonte: Elaboração própria.

Outros atributos apresentaram divergência de percepção. Entre eles estão: atuação transparente da gestão superior, currículos atualizados e planos de ensino adequados, atuação administrativa das pró-reitorias e formação profissional adequada ao mercado. A exceção da transparência da gestão superior, que pode rapidamente ser melhorada com o compartilhamento da gestão e informação de suas ações, os outros três pontos estão intimamente relacionados com a inclusão de informação sobre as dinâmicas comportamentais do mercado de trabalho e das ondas produzidas pela sociedade com respeito a produtos, tecnologias e serviços, podem ser enfrentados fazendo-se ajuste nos conteúdos e focar nas demandas dos mercados de trabalho, tecnologia, informação, conhecimento e serviços nas diversas áreas de competência da UFRA.

\subsection{Ambiente Externo: Oportunidades e Ameaças}

O ambiente externo contempla as forças sobre as quais a instituição não exerce controle, mas ao conhecê-las pode se preparar para construir estratégias sustentáveis para atuar nesse ambiente. Tais forças foram reunidas no grupo de oportunidades e de ameaças ao desempenho da UFRA. Na Figura 2 , apresentam-se os resultados integrados das percepções dos professores e dos egressos. 
Os atributos de oportunidades e ameaças apresentaram correlação de 0,779 , significativo a $1 \%$. Isto indica uma alta associação entre as percepções dos professores e dos egressos quanto a tais atributos.

Dentre os nove atributos, os professores elegeram oito como sendo oportunidades e apenas uma ameaça. Por sua vez, os egressos identificaram oito oportunidades e uma ameaça, sendo que ambas as percepções foram coincidentes (Figura 2). Este resultado pode ser considerado de extrema relevância para a UFRA construir suas estratégias, levando em consideração seus pontos fortes para imediatamente participar e dominar esse cenário.

As oportunidades reveladas permitem à UFRA participar dos cenários atuais de fronteira que estão determinando os rumos do nosso campo de ação para os próximos 50 anos. O código florestal, a agropecuária de baixo carbono, as tecnologias apropriadas e a estruturação de cadeias produtivas estão todas dentro de nossas competências e exigem ações imediatas para se tornar campo de domínio para a UFRA se tornar referência, sobretudo na Amazônia em que temos vantagens comparativas que podem ser transformadas em vantagens competitivas sustentáveis.

Essas oportunidades devem ser imediatamente incorporadas nas matrizes curriculares e integrar os eixos temáticos dinâmicos dos diversos cursos dos campi da UFRA.

A implantação do código florestal abre espaço para a inserção e propagação dos sistemas produtivos da agropecuária de baixo carbono (ABC), que envolve a produção diversificada, SAFs e sistemas extrativistas da agricultura familiar, os sistemas envolvendo a dinâmica lavoura-pecuáriafloresta e os diversos sistemas silvipastoris, os sistemas extrativistas, os sistemas de silviculturas com o plantio de árvore em monocultivo e os sistemas integrados como a produção do óleo de palma, fruticultura, pecuária de leite, pesca, aquicultura e avicultura.

A estruturação das cadeias envolve os novos sistemas de produção de grãos em plantio direto, pecuária em novos manejos de pasto, valoração da floresta para as cadeias de produtos madeireiros e não madeireiros, fruticultura, extração sustentável de minérios e pesca sustentável. Essas novas alternativas e sistemas de uso da terra e da floresta exigem uso intensivo de tecnologia de informação e conhecimento, energias alternativas, modelos integrados de gestão, biotecnologias, inovações diversas e, sobretudo, maior nível de conhecimento, organização e integração das cadeias produtivas de base agrária e não agrária. 


\section{Figura 2. Visão do ambiente externo das oportunidades e das ameaças para a UFRA de acordo com a percepção dos professores e egressos,}

Pará, 2014.

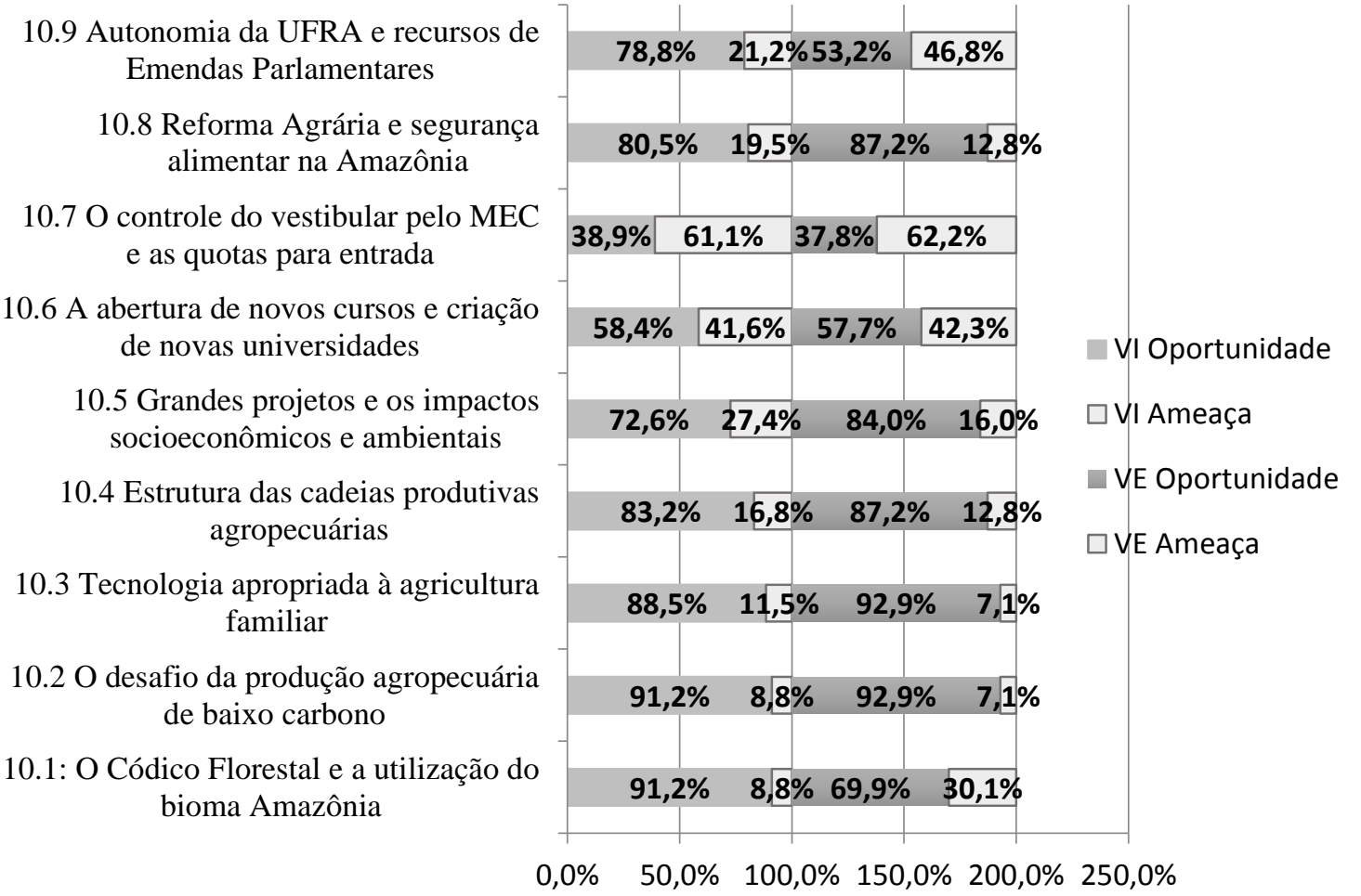

Fonte: Dados da pesquisa.

A única ameaça revelada na percepção dos professores e dos egressos diz respeito ao controle do vestibular pelo MEC e a disponibilidade de quotas para permitir a entrada na universidade de grupos socialmente excluídos. Esse ponto exige que a UFRA crie uma estratégia para identificar talentos no ensino médio em geral, com foco nos grupos enquadrados nas quotas, desenvolver 0 marketing para despertar o interesse pelos cursos da UFRA e contribuir para melhorar seus escores em relação aos demais concorrentes. Com isso, podese conseguir com maior facilidade o preenchimento das vagas dos cursos com os candidatos locais. O segundo ponto diz respeito ao emprego de um peso diferencial para beneficiar os candidatos locais, relativamente aos de outras unidades da federação, que dificilmente virão fazer matrícula, sobretudo nos cursos dos campi do interior.

\subsection{Análise Fatorial e Cenários}

A AFE foi utilizada para atender a dois princípios fundamentais de um planejamento estratégico com efetiva participação da sociedade. O primeiro incorpora o rigor científico necessário à definição dos graus de significância dos fatores que influenciam os ambientes interno e externo e o segundo visa sedimentar, no essencial, a construção de cenários claros e representativos da participação social e de relativa facilidade de compreensão, além de como facilitar a elaboração dos objetivos e das metas integrantes das ações estratégias que devem ser elaboradas, implementadas e conduzidas pela 
UFRA. Portanto, os resultados gerados pela AFE permitiram fazer a compatibilização das dimensões estratégicas, identificar as variáveis associadas a cada dimensão e facilitar a revelação das afinidades de cada uma delas pelos órgãos da gestão institucional que têm a missão de executar 0 planejamento. Com isto, agregam-se vantagens competitivas a cada estratégia.

A AFE permitiu operacionalizar o cruzamento das forças delineadas pela matriz fofa e, a partir dos resultados, construir os seguintes cenários em apoio ao estabelecimento de estratégias e o desenho dos mapas de implantação, acompanhamento e controle, que serão objeto de trabalho da próxima rodada do Ciclopi. O primeiro cenário foi especificado para representar a combinação entre os pontos fortes internos e as oportunidades externas, para a elaboração de estratégias ofensivas e capazes de criar vantagens competitivas sustentáveis. O segundo cenário foi desenhado pela composição entre os pontos fortes internos e as ameaças externas, com vistas a criar estratégias para reforçar as forças do ambiente atual e pelo menos continuar com o desempenho inercial, ou de conformismo, em relação aos fins institucionais. No terceiro cenário, fez-se a interação entre os pontos fracos internos e as oportunidades externas, que requer a criação de uma força tarefa para mudar 0 quadro interno e possibilitar o aproveitamento das oportunidades externas. No quarto cenário, admite-se, no ambiente interno, uma situação de conformismo, desmotivação e descompromisso com os fins institucionais e, no ambiente externo, as dificuldades que configuram uma "situação trágica", que deve ser considerada como movimentos atípicos para os quais a instituição deve se preparar e fazer as alterações no status quo e manter seu nível de participação no mercado. Por fim, neste texto apresenta-se apenas o primeiro cenário, por limitação do número de páginas.

Os resultados estão reunidos nas Tabelas 1, 2, 3 e 4 obedecendo os respectivos cenários construídos a partir do cruzamento das forças definidoras dos ambientes analíticos interno e externo da UFRA. As informações contidas nas tabelas foram geradas a partir da especificação de um modelo fatorial em que as variáveis foram submetidas a uma análise exploratória dos dados, requisito necessário para se obtiver as soluções teoricamente mais significativas e representativas do fenômeno estudado.

Com efeito, as matrizes de correlação apresentaram determinantes diferentes de zero, logo admitem inversas e a solução resultante é única e teoricamente representativa do fenômeno. De acordo com os testes KMO situados acima de 0,63 (superior ao limite aceitável de 0,50) e os testes de esfericidade de Bartlett significativos a $1 \%$, a mostra adequa-se à AFE. As cargas fatoriais estimadas apresentaram significância a $1 \%$ e os modelos representam os cenários estudados. Todas as comunalidades situaram-se acima de 0,50, o que atesta suas importâncias na definição das dimensões latentes. Por fim, os fatores extraídos explicaram mais de $60 \%$ da variância total dos dados. Sendo assim, considera-se que o modelo de AFE foi bem especificado e os resultados são considerados bons. 


\subsubsection{Cenário 1: Fortalezas e Oportunidades}

Esse cenário representa a situação do melhor dos horizontes para UFRA. Nesta perspectiva, embora os resultados revelem que há forte inercialidade (acomodação) para aceitar, ao invés de reagir, a situação das forças internas, aponta-se um caminho, identificado a partir das percepções dos grupos de interesse, que pode levar a instituição a uma nova posição competitiva, desde que haja uma mudança de atitude na conjugação das potencialidades internas com foco nas oportunidades reveladas e que estão flutuando ao seu alcance.

O cenário 1 foi configurado em conformidade com os resultados da AFE apresentados na Tabela 1, em cinco fatores ou dimensões latentes a serem alcançadas. Cabe lembrar que são situações potenciais e que, para alcançalas, a UFRA necessita estabelecer estratégias adequadas e mapear as formas para obter êxito.

O primeiro fator explicou $18,86 \%$ da variância total e representa a força conjunta de quatro variáveis, que refletem, na percepção dos entrevistados, 0 avanço e estruturação de cadeias produtivas, o desenvolvimento de tecnologias apropriadas para atender aos desafios da sustentabilidade da agricultura familiar, o desafio da implantação e expansão da agropecuária de baixo carbono, a compensação por danos ambientais de grandes projetos e as externalidades socioeconômicas, que estão fortemente associadas com a missão da UFRA de contribuir para o desenvolvimento sustentável e, por isso, pode ser nominado de dimensão sustentabilidade institucional.

O segundo fator, ou dimensão latente, explicou $16,56 \%$ da variância total e representa as forças integradas na capacidade de administração das próreitorias, das coordenadorias de curso, da transparência da gestão superior e a expansão multicampi da UFRA que, em conjunto, caracterizam sua capacidade de gestão estratégica no que tange ao propósito da consolidação como IFES na Amazônia, por isso pode ser denominada de dimensão gestão estratégica. Observa-se que as maiores cargas fatoriais estão associadas às pró-reitorias e coordenadorias de curso, que representam as forças geradoras das políticas internas e, portanto, o motor desencadeador das ações para tornar o cenário uma realidade, conforme Porter (1999) e Santana (2007).

O terceiro fator representa a integração das forças comunicação e marketing institucional, atributos profissionais exigidos pelo mercado e formação de profissional ajustado às demandas do mercado, que pode ser denominado de dimensão ressonância do mercado. Esta dimensão necessita de redesenho, começando pela comunicação e marketing que tem a maior carga fatorial e, se realinhada, tende a produzir o maior impacto positivo para à concretização do cenário.

O quarto fator representa a relação entre a UFRA e o egresso e pode ser denominado de dimensão vantagem competitiva específica. $O$ egresso pode ser considerado como o indicador de desempenho competitivo da UFRA, dado que a parcela do número de formados que entra no mercado de trabalho, envolvendo as diversas formas de ocupação e emprego, quando comparado com outras instituições, revela o grau de vantagem competitiva da instituição. 
Portanto, uma boa relação entre a UFRA e os egressos pode funcionar como fonte de informação para se desenhar planos de marketing voltados para afirmar a posição da instituição na região e no Brasil.

\begin{tabular}{|c|c|c|c|c|c|c|}
\hline Variáveis & $\begin{array}{c}\text { Fator } \\
1\end{array}$ & $\begin{array}{c}\text { Fator } \\
2\end{array}$ & $\begin{array}{c}\text { Fator } \\
3\end{array}$ & $\begin{array}{c}\text { Fator } \\
4\end{array}$ & $\begin{array}{c}\text { Fator } \\
5\end{array}$ & $\begin{array}{c}\text { Comunal } \\
\text { idade }\end{array}$ \\
\hline V22 OportunidadeAgrBCarbono & 0,749 & 0,020 & $-0,093$ & 0,033 & $-0,145$ & 0,592 \\
\hline V23 OportunidadeTAFamiliar & 0,815 & $-0,002$ & 0,022 & $-0,042$ & $-0,042$ & 0,668 \\
\hline V24 OportunidadeACProdutiva & 0,856 & $-0,021$ & $-0,020$ & 0,026 & 0,055 & 0,737 \\
\hline V25 OportunidadeGProjeto & 0,686 & 0,040 & $-0,048$ & 0,058 & 0,177 & 0,510 \\
\hline V9 PforteExMulticCampi & 0,023 & 0,596 & 0,008 & $-0,409$ & $-0,403$ & 0,685 \\
\hline V10 PforteADMProreitoria & 0,046 & 0,850 & 0,043 & $-0,022$ & 0,112 & 0,740 \\
\hline V11 PforteADMCoordenador & 0,033 & 0,741 & 0,021 & 0,204 & 0,180 & 0,625 \\
\hline V12 PforteGSTransparênte & $-0,028$ & 0,645 & 0,394 & 0,065 & 0,037 & 0,578 \\
\hline V14 PforteCMarketing & $-0,037$ & 0,081 & 0,787 & 0,171 & 0,062 & 0,660 \\
\hline V7 PforteFormaMercado & $-0,106$ & 0,422 & 0,501 & 0,186 & $-0,195$ & 0,513 \\
\hline V30 AProfissional & $-0,049$ & 0,043 & 0,618 & $-0,512$ & 0,098 & 0,658 \\
\hline V16 PforteUfraEgresso & 0,055 & 0,148 & 0,178 & 0,804 & $-0,039$ & 0,705 \\
\hline V27 OportunidadeCVMec & 0,027 & 0,174 & 0,044 & $-0,066$ & 0,872 & 0,797 \\
\hline Soma de quadrados das cargas & 2,452 & 2,284 & 1,455 & 1,197 & 1,078 & 8,466 \\
\hline Percentual do traço (\%) & 18,863 & 17,565 & 11,191 & 9,211 & 8,296 & 65,126 \\
\hline
\end{tabular}

Adequação da amostra: Teste $\mathrm{KMO}=0,718$; Teste de Bartlett $\left(\chi^{2} 78 \mathrm{gl}\right)=771,17(\mathrm{p}$-valor $=$ $0,0000)$

Fonte: Elaboração própria.

Não obstante essa relação de parceria esteja sendo negligenciada, ou não oportunizada pela UFRA, define um fator estratégico dentro do cenário. Portanto, o padrão de comunicação deve ser redimensionado para captar e interagir com o egresso.

O quinto e último fator representa o controle do vestibular pelo MEC e o estabelecimento de quotas, que pode ser denominada de dimensão autonomia institucional. $O$ enfrentamento virtuoso dessa dimensão exige estratégia inteligente para a identificação de talentos e vocacionar os cotistas para os cursos da UFRA. Ao contemplar esse atributo, a estratégia pode tornar-se sustentável e de difícil superação pelos concorrentes, uma vez que tende a se materializar na forma de conceito e, ao ser disseminado dessa forma, fideliza o grupo de interesse. Por outro lado, se nada for feito para se tirar proveito dessa política, os efeitos podem se transformar em ameaça.

Este cenário representa a força máxima que a UFRA dispõe para criar vantagens competitivas sustentáveis, fazendo uso adequado de seus pontos fortes para aproveitar todas as oportunidades que podem ser conquistadas nos diversos horizontes de tempo.

A visão macro, configurada na dimensão sustentabilidade institucional, revela um ambiente de oportunidades extremamente favorável para a UFRA, ao contemplar planos e programas de escopo regional, nacional e global. O primeiro se refere ao Plano ABC (Plano Setorial de Mitigação e da 
Adaptação às Mudanças Climáticas Visando à Consolidação de uma Economia de Baixa Emissão de Carbono na Agricultura), conforme ASSAD (2014), cujas premissas abrangem as práticas mais eficientes de mitigação de impactos ambientais e da geração de emprego e renda aos produtores e empresários. Entre as tecnologias apropriadas, destacam-se o manejo de recursos naturais para prevenção e controle de desmatamento, a extração de produtos madeireiros e não madeireiros, a recuperação de pastagens degradadas, a integração dos sistemas lavoura-floresta, lavoura-pecuária, lavoura-pecuáriafloresta, o plantio direto, a fixação biológica de nitrogênio, o plantio de florestas, o tratamento de dejetos animais e de resíduos de agroindústrias, a integração da agricultura familiar à agroindústria de processamento e os demais sistemas diversificados de produção.

Nessa dimensão, a Amazônia Legal apresenta-se como espaço com grande vazio de profissionais de ciências agrárias, ciências sociais aplicadas, ciências ambientais, tecnologias da informação e conhecimento, engenharias diversas, com perfil para participar desse ambiente na Amazônia, cujos resultados devem ser alcançados no âmbito da Política Nacional de Mudança do Clima devem aparecer até 2020 (SANTANA, 2014a). Embora o Brasil conte com 273 universidades com cursos de ciências agrárias, as regiões Norte, Nordeste e Centro-Oeste, enfrentam grandes limitações para a integração das universidades com raio de até $200 \mathrm{~km}$. Na Amazônia, que mais precisa da eficácia das políticas de desenvolvimento regional e dos programas voltados ao desenvolvimento sustentável, deficiência é grande.

Por conta disso, as ações estratégicas da UFRA devem ser orientadas para dominar essas temáticas (ajustar a formação dos profissionais, criar cursos adequados e fortalecer os campi para que aproveitem as vantagens locacionais), porque os concorrentes estão desenvolvendo estudos e criando tecnologias em nosso campo de atuação e tomando o espaço em áreas estratégicas como a da microrregião de Paragominas.

No ambiente microanalítico, a dimensão mais importante para a interação dos pontos fortes com as oportunidades se refere à gestão estratégica para demarcar e dominar o espaço geográfico de atuação da instituição com cursos formando profissionais ajustados ao mercado e as demandas sociais. Portanto, cabe a cada pró-reitoria e coordenadoria de curso fazer uma leitura deste cenário para superar a situação convencional e, de forma integrada, elaborar estratégias com foco na criação de vantagens competitivas sustentáveis.

A outra dimensão que necessita criar um diferencial nas capacidades de gestão competitiva é a de ressonância de mercado, que continua atuando na posição de "meio de campo" porque falta compreender o mercado, os grupos de interesse, o poder da transversalidade da comunicação e marketing e 0 diferencial competitivo que a instituição possui para atuar neste cenário.

A posição de "meio de campo", segundo Porter (1999), é uma situação estratégica pobre, porque reflete um baixo desempenho institucional. Isto, geralmente, pode ser atribuído a uma indefinição da cultura institucional, do conjunto de arranjos organizacionais e do sistema de motivação da comunidade, que foi definido no seio do modelo burocrático padrão e, ainda, continua fortemente arraigados na maioria das IFES. Para reverter essa 
posição, a instituição deve mudar de atitude e tomar decisões estratégicas, considerando a participação dos grupos de interesse, para se diferenciar e conquistar novas parcelas de mercado.

\subsubsection{Cenário 2: Fortalezas e Ameaças}

O cenário 2 pode ser elaborado, conforme os resultados da Tabela 2, com seis fatores ou dimensões latentes a serem alcançados nas ações do desenvolvimento institucional. Cabe lembrar que o cenário é uma situação potencial e que, para atingi-la, a UFRA necessita estabelecer estratégias adequadas e mapear as formas de implantação, avaliação e controle.

\section{Tabela 2. Matriz de cargas fatoriais do cenário fortalezas e ameaças após a rotação ortogonal pelo método varimax, Pará, 2014.}

\begin{tabular}{lccccccc}
\hline Variáveis & $\begin{array}{c}\text { Fator } \\
\mathbf{1}\end{array}$ & $\begin{array}{c}\text { Fator } \\
\mathbf{2}\end{array}$ & $\begin{array}{c}\text { Fator } \\
\mathbf{3}\end{array}$ & $\begin{array}{c}\text { Fator } \\
\mathbf{4}\end{array}$ & $\begin{array}{c}\text { Fator } \\
\mathbf{5}\end{array}$ & $\begin{array}{c}\text { Fator } \\
\mathbf{6}\end{array}$ & $\begin{array}{c}\text { Comun } \\
\text { alidade }\end{array}$ \\
\hline V10 PforteADMProreitoria & $\mathbf{0 , 6 7 1}$ & 0,401 & 0,026 & $-0,179$ & $-0,074$ & $-0,208$ & 0,693 \\
V11 PforteADMCoordenador & $\mathbf{0 , 7 2 4}$ & 0,104 & $-0,038$ & $-0,060$ & $-0,015$ & $-0,177$ & 0,571 \\
V12 PforteGSTranspa & $\mathbf{0 , 6 8 0}$ & 0,157 & 0,096 & $-0,199$ & $-0,092$ & 0,086 & 0,552 \\
V15 PforteUfraProdutor & $\mathbf{0 , 6 0 3}$ & $-0,021$ & 0,064 & 0,145 & 0,460 & 0,196 & 0,640 \\
V16 PforteUfraEgresso & $\mathbf{0 , 5 5 0}$ & $-0,423$ & $-0,250$ & 0,142 & $-0,039$ & 0,020 & 0,565 \\
V8 PforteCursoNCAmpi & 0,141 & $\mathbf{0 , 6 1 6}$ & $-0,238$ & 0,245 & $-0,178$ & $-0,282$ & 0,627 \\
V9 PforteEXMulticampi & 0,284 & $\mathbf{0 , 7 2 2}$ & 0,139 & $-0,157$ & 0,062 & 0,126 & 0,665 \\
V24 AmeaçaACProdutiva & 0,065 & $-0,099$ & $\mathbf{0 , 7 6 5}$ & 0,241 & $-0,103$ & $-0,070$ & 0,673 \\
V25 AmeaçaGProjeto & $-0,045$ & 0,116 & $\mathbf{0 , 7 5 8}$ & $-0,041$ & 0,106 & 0,062 & 0,607 \\
V27 AmeaçaCVMec & $-0,196$ & 0,311 & $-0,028$ & $\mathbf{0 , 5 1 2}$ & 0,124 & 0,313 & 0,511 \\
V29 AmeaçaAUfraPolitico & $-0,097$ & $-0,110$ & 0,127 & $\mathbf{0 , 7 5 9}$ & 0,070 & 0,032 & 0,620 \\
V2 Sexo & $-0,047$ & $-0,070$ & 0,075 & 0,143 & $\mathbf{0 , 8 0 8}$ & $-0,244$ & 0,746 \\
V23 AmeaçaTAFamiliar & 0,089 & $-0,139$ & 0,271 & 0,466 & $-\mathbf{0 , 5 2 1}$ & $-0,324$ & 0,694 \\
V26 AmeaçaNCAeNUniv & $-0,038$ & $-0,054$ & 0,007 & 0,089 & $-0,124$ & $\mathbf{0 , 8 4 4}$ & 0,740 \\
\hline Soma de quadrados das & & & & & & & \\
cargas & 2,269 & 1,435 & 1,41 & 1,345 & 1,245 & 1,200 & 8,904 \\
Percentual do traço (\%) & 16,208 & 10,252 & 10,074 & 9,608 & 8,896 & 8,575 & 63,613 \\
\hline Adequaça dama amos
\end{tabular}

Adequação da amostra: Teste KMO $=0,634$; Teste de Bartlett $\left(\chi^{2} 78 \mathrm{gl}\right)=481,33(p$-valor $=0,00)$ Fonte: Elaboração própria.

O primeiro fator ou dimensão latente explicou 16,2\% da variância total e representa a interação de cinco variáveis com cargas fatoriais significativas (gestão dos coordenadores, gestão superior transparente, gestão das próreitorias, interação da UFRA com a sociedade e interação da UFRA com o egresso), cuja dimensão pode ser denominada de gestão compartilhada. Todas as variáveis constituem pontos fortes cujas forças se complementam, 0 que aumenta o poder da estratégia para não apenas neutralizar, mas superar as ameaças. Esta dimensão representa o DNA do desenvolvimento sustentável da UFRA. Nada de abrangente tende a acontecer se os representantes das 
unidades de gestão, em conjunto, não se engajarem no planejamento e execução dos projetos em todas as áreas.

O segundo fator explicou 10,25\% da variância total dos dados e representa o efeito de duas variáveis (criação de novos cursos e expansão multicampi da UFRA) que pode ser denominado de dimensão escopo geográfico, que se volta para o domínio do território com os cursos ajustados às demandas locais e regionais nas diversas áreas de competência. Esta dimensão requer estratégias muito bem definidas porque exige escolha adequada de locais e de cursos em conformidade com as potencialidades das cadeias de negócios, a disponibilidade de recursos humano e de capital, e as condições de infraestrutura de transporte, saúde, educação e comunicação.

O terceiro fator é composto pelas seguintes variáveis: ameaça à estruturação de cadeias produtivas e ameaça a implantação de grandes projetos na Amazônia e pode ser nominado por dimensão crescimento econômico. Esta dimensão incorpora a preocupação com os desmatamentos e a escolha e uso de sistemas produtivos mitigadores de impactos socioambientais. Na dinâmica atual, conforme Santana (2008), Santana (2012), Santana et al. (2013) e Santana et al. (2014), as cadeias produtivas em processo de consolidação e os grandes projetos para a produção de energia elétrica e para implantação de portos e hidrovias, causam elevados danos sociais e ambientais e que a UFRA deve desenvolver estratégias para apoiar a sociedade amazônica a reivindicar direitos sobre as condições de bem-estar reais e potencias perdidas.

Estas ameaças ao crescimento regional podem ser revertidas por meio da efetiva implementação, com o apoio deliberado da gestão superior da UFRA a projetos como "A UFRA na Reforma Agrária", os projetos sobre "cadeias produtivas, arranjos produtivos locais, valoração dos recursos naturais e estimação das compensações por danos ambientais de grandes projetos" conduzidos pelo Grupo de Pesquisa Gecads, do realinhamento de linhas de pesquisa dos cursos de pós-graduação e a criação de planos didáticos de pesquisa-ação como "A UFRA na Comunidade", "Projeto Carroceiros" e tantos outros projetos e programas para ampliar a escala dos conhecimentos e dos fluxos de resultados a serem aplicados a maior número de grupos sociais.

O quarto fator está associado às ameaças produzidas pelas variáveis controle do vestibular pelo MEC e a interação da UFRA com políticos para aprovar emendas parlamentares e pode ser denominado de dimensão autonomia institucional. Esta dimensão sinaliza para a suplementação de orçamento e ajustamento no suprimento de vagas dos cursos demandados. A dimensão pesa contra as duas anteriores, portanto, a estratégia deve levar em conta essas relações antagônicas. As pró-reitorias e coordenações de cursos devem ampliar as iniciativas de criar mecanismos para neutralizar as ameaças.

O quinto fator contempla as variáveis sexo dos entrevistados e ameaça de tecnologia para agricultura familiar que pode ser definido por dimensão gênero e inclusão social. Os projetos de assentamento de reforma agrária e do extrativismo possibilitaram a ampliação e o domínio da mulher como gestora dos estabelecimentos, com vistas a contribuir para a segurança alimentar e aumentar a qualidade de vida das famílias. A UFRA está acompanhando a tendência de as mulheres atuarem como gestoras à frente de pró-reitorias, 
coordenações de cursos e diretoras de instituto e campi. Aqui cabe o olhar da gestão de competência para ajustar a formação dos alunos para às demandas do mercado e, especificamente, desses grupos excluídos da Amazônia.

O sexto fator representa apenas a variável ameaça pela abertura de novos cursos e universidades que constitui a dimensão concorrência ou rivalidade institucional. Esta dimensão exige uma mudança de atitude da UFRA, de defensiva para ofensiva, porque não se pode aceitar perdas de espaço, recursos, prestígio e oportunidade de ampliação para os concorrentes. É necessário conhecer a necessidade efetiva de cursos e de vagas, bem como a demanda por profissionais com habilidade nas áreas do ensino, pesquisa e tecnologia, serviços de assistência técnica, gestores, consultores e empreendedores, conforme estudos recentes de cadeias produtivas, arranjos produtivos locais e desenvolvimento rural na Amazônia contidos em Santana (2014b).

Neste cenário, tem-se duas dimensões fortes e que representam $26,46 \%$ da variância comum contra quatro dimensões que reúnem $37,15 \%$ da variância. Portanto, é necessário cautela na elaboração das estratégias para ter condições de mudar o ambiente e neutralizar as ameaças.

Em geral, os resultados deste estudo já são um diferencial competitivo em relação aos concorrentes, porque não se dispõe de informações estratégicas de ampla representatividade sobre os ambientes micro e macroanalíticos, compatibilizadas e alinhadas para ampliar o espaço ocupado e conquistar novas parcelas do mercado.

\subsubsection{Cenário 3: Fraquezas e Oportunidades}

Este cenário representa a posição atual do ambiente interno de fraquezas com a fronteira de oportunidades revelada e pode ser dimensionado, conforme os resultados da Tabela 3, com cinco fatores ou dimensões latentes. Este cenário representa a associação das variáveis indicadoras de fraquezas com as indicadoras de oportunidades e contribui para o alinhamento das ações com 0 propósito de aumentar as chances de aproveitamento das oportunidades. Essas dimensões representam situações potenciais e, para alcança-las, a UFRA necessita estabelecer estratégias adequadas e mapear as formas de implantação, avaliação e controle.

O primeiro fator, ou dimensão latente, explicou 16,6\% da variância total, é formado pela interação de quatro variáveis com cargas fatoriais significativas e que representam oportunidades para UFRA (estruturação de cadeias produtivas, tecnologia apropriada para agricultura familiar, reforma agrária e segurança alimentar, compensação de grandes projetos por danos ambientais) cada dimensão, os cursos de ciências agrárias, engenharia ambiental, sistema de informação, contabilidade e administração devem alinhar o foco para produzir solução para os problemas criados pela expansão da produção e do consumo de produtos rurais e industriais, a partir do campus Belém que abriga a matriz de maior conhecimento geral, com articulação direta com os demais campi e as cadeias produtivas em que o território é 
especializado, conforme Santana (2012; 2014b). Atuando desta forma, em pouco tempo a marca de uma UFRA viva e participativa pode ser impressa e divulgada na Amazônia.

O segundo fator contempla as variáveis fraquezas da comunicação e marketing institucional, da relação entre a UFRA e os egressos, da interação entre a UFRA e os produtores, as empresas e as comunidades e da gestão superior transparente, que pode ser denominado por dimensão comunicação ineficaz. A instituição necessita obter o feedback do mercado e se comunicar com os grupos de interesse para criar as economias de informação e conhecimento. Desprezar essa força é continuar tomando decisão na defensiva e permanecer na inércia da posição de "meio-termo". Cabe lembrar, todavia, que este tipo de comportamento tem mais de meio século e a gestão atual é fruto desta trajetória histórica que vem perdendo espaço e competitividade. Portanto, deve-se entender que a UFRA é um todo e a gestão é apenas uma parte temporária em atuação, logo deve mudar de atitude para operar nessa nova geopolítica regional, nacional e global e alcançar novo patamar de desenvolvimento.

Tabela 3. Matriz de cargas fatoriais do cenário fraquezas e oportunidades após a rotação ortogonal pelo método varimax, Pará, 2014.

\begin{tabular}{|c|c|c|c|c|c|c|}
\hline Variáveis & $\begin{array}{c}\text { Fator } \\
1\end{array}$ & $\begin{array}{c}\text { Fator } \\
2\end{array}$ & $\begin{array}{c}\text { Fator } \\
3\end{array}$ & $\begin{array}{c}\text { Fator } \\
4\end{array}$ & $\begin{array}{c}\text { Fator } \\
5\end{array}$ & $\begin{array}{c}\text { Comunalida } \\
\text { de }\end{array}$ \\
\hline V23 OportunidadeTAFamiliar & 0,800 & 0,107 & 0,070 & $-0,001$ & $-0,042$ & 0,658 \\
\hline V24 OportunidadeACProdutiva & 0,860 & 0,009 & 0,060 & $-0,043$ & $-0,003$ & 0,745 \\
\hline V25 OportunidadeGProjeto & 0,700 & 0,012 & $-0,054$ & 0,001 & 0,128 & 0,509 \\
\hline V28 OportunidadeRAeSAlim & 0,765 & 0,092 & $-0,094$ & 0,053 & 0,052 & 0,609 \\
\hline V12 PfracoGSTransparente & 0,079 & 0,618 & 0,420 & 0,024 & $-0,002$ & 0,565 \\
\hline V14 PfracoCMarketing & 0,040 & 0,778 & 0,111 & 0,106 & 0,083 & 0,638 \\
\hline V15 PfracoUfraProdutor & 0,030 & 0,703 & 0,143 & $-0,082$ & $-0,032$ & 0,524 \\
\hline V16 PfracoUfraEgresso & 0,093 & 0,765 & 0,021 & 0,108 & 0,008 & 0,606 \\
\hline V9 PfracoExMulticampi & $-0,022$ & 0,053 & 0,670 & $-0,029$ & 0,251 & 0,516 \\
\hline V10 PfracoADMProreito & $-0,008$ & 0,182 & 0,780 & 0,158 & $-0,080$ & 0,673 \\
\hline V11 PfracoADMCoordenadoria & $-0,017$ & 0,224 & 0,680 & 0,056 & $-0,180$ & 0,548 \\
\hline V27 OportunidadeCVMec & 0,065 & $-0,003$ & $-0,080$ & $-0,944$ & 0,046 & 0,903 \\
\hline V27 AmeaçaCVestMec & 0,075 & 0,123 & 0,078 & 0,933 & 0,050 & 0,900 \\
\hline V26 OportunidadeNCAeNUniv & 0,028 & 0,062 & $-0,245$ & $-0,031$ & 0,725 & 0,591 \\
\hline V2 Sexo & 0,087 & $-0,015$ & 0,212 & 0,033 & 0,691 & 0,531 \\
\hline $\begin{array}{l}\text { Soma de quadrados das } \\
\text { cargas }\end{array}$ & 2,490 & 2,193 & 1,866 & 1,826 & 1,138 & 9,513 \\
\hline Percentual do traço (\%) & 16,602 & 14,618 & 12,443 & 12,176 & 7,586 & 63,425 \\
\hline
\end{tabular}

Adequação da amostra: Teste KMO $=0,696$; Teste de Bartlett $\left(\chi^{2} 78 \mathrm{gl}\right)=1.089,36(\mathrm{p}$-valor $=$ 0,0000)

Fonte: Dados da pesquisa.

O terceiro fator é formado por três variáveis que indicam fraquezas na gestão de pró-reitores, na gestão de coordenadores e na expansão multicampi, que pode ser denominado de dimensão governança institucional compartilhada. Essa dimensão informa que essas forças, na situação observada, estão atuando como fraquezas, logo devem sair do isolamento e 
trabalhar de forma integrada em prol de um objetivo comum, de forma a produzir ações de reforço e tirar proveito das condições favoráveis.

$\mathrm{O}$ quarto fator representa a dimensão controle do vestibular pelo MEC e pode ser nominado como dimensão autonomia institucional. Esta dimensão representa a estratégia vencedora do MEC no que tange generalizar oportunidades e validar suas ações afirmativas na educação brasileira. Para que o impacto na perda de autonomia quanto à liberdade na escolha de candidato com perfil mais ajustado aos cursos, deve-se desenvolver ações para neutralizar tais efeitos e criar alternativas para se beneficiar da política. $O$ desenvolverem tais ações cabe às pró-reitorias de ensino e de assuntos estudantis.

O quinto fator contempla as variáveis abertura de novos cursos e de novas universidades e a variável sexo do entrevistado, e representa a dimensão rivalidade institucional. Nesta dimensão aparece a questão de gênero com significativa carga fatorial e associada com a abertura de novos cursos e de novas instituições, que revelou a influência equilibrada das mulheres (professoras e egressas) na definição das ações da UFRA.

Este cenário indica que a fraqueza tem peso maior do que a oportunidade e pede o desenvolvimento de estratégias de reforço na gestão de pessoas, de competências para desenvolver e integrar ações focando essa dimensão cuja participação da UFRA é insignificante. Esse reforço deve iniciar com a mudança no sistema de motivação para a construção de capital social e capital humano, dentro de uma atuação de maior transparência, com 0 compartilhamento de decisões e a reorientação dos arranjos organizacionais visando obter resultados em todos os níveis. Isto exige, adicionalmente, uma mudança de atitude na direção de uma clara definição cultural da instituição.

\subsubsection{Cenário 4: Fraquezas e Ameaças}

O cenário 4 representa o pior dos mundos de uma instituição por alinhar as forças que apresentam debilidade para enfrentar um ambiente externo de ameaças e pode ser dimensionado, conforme resultados da Tabela 4, com cinco fatores ou dimensões latentes e que devem fundamentar a criação de estratégias. Estas dimensões refletem situações potenciais e, para enfrentalas, a UFRA necessita estabelecer planos estratégicos adequados e mapear suas formas de implantação, avaliação e controle.

O primeiro fator ou dimensão latente explicou $17,07 \%$ da variância comum e representa a interação de quatro variáveis com cargas fatoriais significativas entre os pontos fracos (comunicação e marketing, relação entre a UFRA e os egressos, relação entre a UFRA e os produtores, as empresas e as comunidades e a gestão superior transparente) que pode ser denominado de dimensão isolamento institucional. Esta dimensão deve ser caracterizada por uma posição defensiva ao se contentar com as ações de paternalismo do MEC e valorizar o saber convencional. Todavia, deve-se explorar o prestígio institucional, alertar para sua contribuição com o desenvolvimento sustentável, compreender o mercado e ampliar a comunicação com os grupos de interesse 
de modo a criar as condições para fugir da posição de "meio de campo". Isto significa investir na construção de capital social e capital humano para movimentar as bases sinérgicas das forças internas com vistas a alavancar a trajetória da expansão multicampi.

O segundo fator explicou $14,18 \%$ da variância total e contempla três variáveis indicadoras da gestão de pró-reitorias, gestão de coordenadorias e expansão multicampi, que pode ser denominado de dimensão gestão compartilhada por se refletir a visão dos grupos de interesse que avaliaram como pontos fracos. A elaboração de estratégias para reforçar essa dimensão deve ser compartilhada com os resultados do cenário 1, como forma de equilibrar as forças internas e superar mais rapidamente as fraquezas, uma vez que a missão da UFRA depende fortemente dessa trajetória de expansão.

O terceiro fator é formado por três variáveis que indicam ameaças na estruturação de cadeias produtivas e compensação dos impactos de grandes projetos e pode ser denominado de dimensão sustentabilidade do crescimento. Essa dimensão informa que essas forças atuam, na situação presente, como ameaças e, portanto, devem ser neutralizadas para não comprometer o desempenho institucional.

Tabela 4. Matriz de cargas fatoriais do cenário fraquezas e ameaças após a rotação ortogonal pelo método varimax, Pará, 2014.

\begin{tabular}{|c|c|c|c|c|c|c|}
\hline Variáveis & $\begin{array}{c}\text { Fator } \\
1\end{array}$ & $\begin{array}{l}\text { Fator } \\
2\end{array}$ & $\begin{array}{c}\text { Fator } \\
3\end{array}$ & $\begin{array}{c}\text { Fator } \\
4\end{array}$ & $\begin{array}{c}\text { Fator } \\
5\end{array}$ & $\begin{array}{l}\text { Comunalid } \\
\text { ade }\end{array}$ \\
\hline V12 PfracoGSTransparente & 0,659 & 0,342 & $-0,125$ & 0,094 & 0,021 & 0,576 \\
\hline V14 PfracoCMarketing & 0,781 & 0,089 & 0,070 & 0,163 & $-0,063$ & 0,653 \\
\hline V15 PfracoUfraProdutor & 0,690 & 0,143 & $-0,135$ & $-0,018$ & 0,193 & 0,552 \\
\hline V16 PfracoUfraEgresso & 0,772 & 0,027 & 0,114 & $-0,058$ & $-0,177$ & 0,644 \\
\hline V9 PfracoExMulticampi & 0,070 & 0,549 & $-0,332$ & 0,455 & 0,244 & 0,683 \\
\hline V10 PfracoADMProreito & 0,192 & 0,799 & 0,019 & 0,105 & $-0,056$ & 0,690 \\
\hline V11 PfracoADMCoordoria & 0,233 & 0,718 & 0,109 & $-0,106$ & $-0,048$ & 0,595 \\
\hline V24 AmeaçaACProdutor & 0,022 & $-0,003$ & 0,746 & 0,035 & 0,334 & 0,669 \\
\hline V25 AmeaçaGProjeto & $-0,037$ & 0,072 & 0,771 & 0,095 & $-0,099$ & 0,620 \\
\hline V21 AmeaçaCod.florestal & 0,070 & 0,070 & 0,142 & 0,694 & 0,016 & 0,512 \\
\hline V26 AmeaçaNCAeNUniv & $-0,032$ & 0,477 & 0,103 & $-0,528$ & $-0,098$ & 0,528 \\
\hline V23 AmeaçaTAFamiliar & $-0,030$ & $-0,047$ & 0,202 & 0,139 & 0,819 & 0,733 \\
\hline V2 Sexo & 0,026 & 0,043 & 0,160 & 0,492 & $-0,531$ & 0,552 \\
\hline $\begin{array}{l}\text { Soma de quadrados das } \\
\text { cargas }\end{array}$ & 2,220 & 1,844 & 1,422 & 1,301 & 1,221 & 8,008 \\
\hline Percentual do traço (\%) & 17,074 & 14,185 & 10,937 & 10,007 & 9,395 & 61,598 \\
\hline
\end{tabular}

Adequação da amostra: Teste KMO $=0,691$; Teste de Bartlett $\left(\chi^{2}\right)=529,85$ (p-valor $=$ 0,0000)

Fonte: Elaboração própria.

O quarto fator inclui as variáveis que refletem ameaça da implantação do código florestal e o bioma Amazônia e da abertura de novos cursos e de novas universidades, e representa a dimensão sustentabilidade institucional. Esta dimensão traduz a situação de bloqueio à estratégia de desenvolvimento institucional com escopo territorial, caso ideologicamente se admita que o agronegócio é um caminho desastroso para a Amazônia e que os novos cursos 
e as novas instituições devem ocupar essa parcela de mercado. Observa-se que a carga fatorial associada à variável criação de novos cursos e de novas universidades apresenta sinal contrário ao da implantação do código florestal, o que reflete a percepção dos grupos de interesse que avaliaram a primeira como oportunidade e a segunda como ameaça.

O quinto fator representa a associação das variáveis tecnologias apropriadas para a agricultura familiar e o sexo dos entrevistados e que pode ser nominado como dimensão sustentabilidade agrária. Como o gênero não reflete, per si, nenhuma situação de fraqueza ou de ameaça, deve-se focar nas atitudes integradas na elaboração dessa estratégia, uma vez que os demandantes de tais tecnologias contemplam um grande percentual de mulheres gestoras, sobretudo nos projetos de assentamentos da Reforma Agrária.

\section{CONSIDERAÇÕES FINAIS}

O estudo revelou as oportunidades que se encontram ao alcance da UFRA. Entre as dimensões favoráveis e estratégicas estão as grandes questões globais com relação à temática ambiental e social. $O$ bioma Amazônia, pela prestação de serviços ambientais, oferta de produtos e a geração de emprego e renda para as comunidades regionais. Igualmente, a agricultura familiar desenvolvida grandemente nos projetos de assentamento da Reforma Agrária representa um dos maiores programas sociais do mundo, senão o maior, ao considerar os programas de crédito, comercialização e de transferência de renda. Portanto, essa fronteira está aberta à UFRA.

Neste contexto, identificou-se, na percepção dos grupos de interesse ligados à UFRA, os pontos fortes, pontos fracos, oportunidades e ameaças à sua trajetória multicampi de desenvolvimento sustentável. A partir desse conhecimento, buscou-se contribuir para ampliar o conhecimento da comunidade acadêmica sobre o ambiente em que atua e apoiar a criação de estratégias competitivas sustentáveis para fortalecer os pontos fortes, superar os pontos fracos, aproveitar as oportunidades e criar barreiras protetoras contra as ameaças ao seu desenvolvimento.

As questões-chave avaliadas pelos grupos de interesse contemplam os principais horizontes que definem a educação para o desenvolvimento da Amazônia e do Brasil nos próximos 50 anos, como as dimensões climáticas, as dimensões que englobam a agropecuária de baixo carbono, a valoração dos recursos naturais, as tecnologias apropriadas aos sistemas de uso da terra e os sistemas industriais, a formação de capital humano e capital social e o desenvolvimento local e sustentável.

A identificação dessas questões-chave lança luz sobre os pontos e as funções a serem corrigidos, redefinidos, substituídos, ou incluídos em novos contextos, tendo em vista gerar um resultado comum para atender aos anseios da comunidade interna e da sociedade. Esses pontos envolvem as reformulações das matrizes curriculares, dos planos didáticos, da atuação dos professores na definição do perfil do profissional, na forma de gestão de pessoas e dos recursos por parte dos coordenadores, diretores e pró-reitores, 
como requisito necessário a viabilização da trajetória de expansão multicampi da UFRA.

Por que é importante atrelar as estratégias voltadas para a expansão multicampi à estruturação territorial de cadeias produtivas e aso grandes projetos de desenvolvimento? Este processo possui características importantes para a geração de sinergias essenciais ao sucesso da consolidação dos campi e dos cursos. As cadeias produtivas são fundamentais para promover 0 adensamento de empresas em todos os setores da economia e para fortalecer as estruturas de Arranjos Produtivos Locais (APLs), que são importantes indutores do empreendedorismo e da interiorização do desenvolvimento. Como os APLs nascem e evoluem sem a influência de políticas públicas, as iniciativas de implantação de novos cursos ancorados neste conceito tornam-se mais sustentáveis.

Com relação ao perfil do profissional que esse novo ambiente de desenvolvimento regional está exigindo, deve-se atentar para os atributos revelados pelas organizações empregadoras em que as qualidades pessoais, a comunicação e expressão e a tecnologia da informação e conhecimento foram indicadas como fundamentais. $\mathrm{Na}$ visão dos professores e egressos aparecem outros atributos extremamente importantes como a economia e gestão de negócios, a valoração de recursos naturais e as qualidades pessoais e ética profissional.

Outro resultado de grande importância estratégica para a inserção da UFRA na fronteira do conhecimento socioeconômico e ambiental, científico e tecnológico e de inovação, diz respeito aos desafios da produção agropecuária de baixo carbono, tecnologias apropriadas para a agricultura familiar e a implantação do código florestal no bioma Amazônia.

O estudo revelou que a estratégia de comunicação e marketing da UFRA é perdedora, na percepção dos grupos de interesse. Este fato também foi revelado nas duas enquetes da Folha de São Paulo em que a UFRA não pontua na relação com o mercado e no último relatório de credenciamento da UFRA pelo MEC em que a comunicação foi considerada insuficiente. Esta questão-chave para o desenvolvimento sustentável da instituição merece realinhamento da comunicação e marketing com foco nos grupos de interesse que, atualmente pode ser enquadrado como ineficaz. Os resultados de ações internas e associadas às forças externas nessa área exigem respostas de curto prazo e com repercussão ampla na sociedade.

Desenvolver as capacidades internas como reforço aos pontos fortes e superar a inércia das atitudes defensivas como estratégia para aproveitar as oportunidades e neutralizar as ameaças que influenciam as ações para alcançar o novo patamar de desenvolvimento. Para isso, existe apenas um caminho sustentável para viabilizar o processo de expansão multicampi que é a construção de capital social e capital humano no seio da comunidade acadêmica.

\section{REFERENCIAS BIBLIOGRÁFICAS}

ASSAD, E. D. Agricultura de baixa emissão de carbono: a evolução de um novo paradigma. Observatório ABC, 2014. 
HAIR JR, J.F.; ANDERSON, R.E.; TATHAM, R.L.; BLACK, W.C. Análise multivariada de dados. Porto Alegre: Bookman, 2005.

JOHNSON, R. A.; WICHERN, D. W. Applied multivariate statistical analysis. New Jersey: Prentice-Hall, 2007.

PORTER, M. E. Competição = on competition: estratégias competitivas essenciais. Rio de Janeiro: Campus, 1999.

SANTANA A. C.; GOMES, S. C.; MOREIRA, M. G. P. Valoração dos impactos socioambientais de grandes projetos e a criação de um fundo de recebíveis para financiar o desenvolvimento na Amazônia. Nota Técnica 01. Belém: IDESP, 2013.

SANTANA, A. C. Cadeias produtivas setoriais e o curso do desenvolvimento local na Amazônia. In: Agricultura tropical: quatro décadas de inovações tecnológicas, institucionais e políticas. Brasília: Embrapa, 2008. v. 2, p. 275-291.

SANTANA, A. C. Métodos quantitativos em economia: elementos e aplicações. Belém, PA: UFRA, 2003.

SANTANA, A. C. Elementos de economia, agronegócio e desenvolvimento local. Belém, PA: UFRA, 2005.

SANTANA, A. C. Índice de desempenho competitivo das empresas de polpa de frutas do Estado do Pará. Revista de Economia e Sociologia Rural. Brasília, v.45, n.4, p.749-775, 2007.

SANTANA, A. C. Mercado, cadeia produtiva e desenvolvimento rural na Amazônia. Belém: UFRA, 2014b.

SANTANA, A. C. Planejamento estratégico institucional da UFRA: 20142024, texto completo. Belém: UFRA, 2014a. 119p.

SANTANA, A. C. Valoração econômica e mercado de recursos florestais. Belém: Universidade Federal Rural da Amazônia (UFRA), 2012.

SANTANA, A. C. Valoração econômica e mercado de recursos florestais. Belém: Universidade Federal Rural da Amazônia (UFRA), 2012.

SANTANA, A. C.; GOMES, S. C.; FERNANDES, A. R.; BOTELHO, M. N. Perfil do profissional de ciências agrárias formado na Universidade Federal Rural da Amazônia: empregadores, graduados e instituições correlatas. Belém: UFRA, 2002.

SANTANA, A. C.; SANTANA, A. L. Aplicação da análise fatorial ao planejamento estratégico de uma Universidade Federal Rural na Amazônia. In: Congresso Brasileiro de Economia, Administração e Sociologia Rural, Goiás, 2014. Anais.... Goiás: SOBER, 2014. p.1-13.

SANTANA, A. C.; SANTANA, SANTANA, Ádamo L.; SANTANA, Ádina L.; SANTOS, M. A. S.; OLIVEIRA, C. M. O. Análise discriminante múltipla do mercado varejista de açaí em Belém do Pará. Revista Brasileira de Fruticultura, Jaboticabal - SP, v.36, n.3, p.532- 541, Setembro 2014. 